\title{
The Fine Structure of the Endogenous Stages of Isospora hemidactyli Carini, 1936 in the Gecko Hemidactylus mabouia from North Brazil
}

\author{
I Paperna, R Lainson*/+
}

Department of Animal Sciences, Faculty of Agriculture, Hebrew University of Jerusalem, Rehovot 76-100, Israel *Departamento de Parasitologia, Instituto Evandro Chagas, Caixa Postal 1128, 66090-000 Belém, PA, Brasil

The ultrastructure is described of the meronts, microgamonts and young oocyst stages of Isospora hemidactyli of the gecko Hemidactylus mabouia from Belém, PA, north Brazil. The endogenous stages all develop in the nucleus of the gut epithelial cells. The nucleus remains intact up to the latest stages of the parasite's development, but degenerates by the time the oocyst appears. Merogonic division appears to be asynchronous, and some of the differentiated merozoites contained more than one nucleus. Microgamonts conform in structure with those of other eimeriids. Some of the type 2 wall-forming bodies disintegrate into smaller globules and ground substance of lower density.

Key words: Isospora hemidactyli - endogenous stages - ultrastructure - Hemidactylus mabouia - gecko - Brazil

Carini (1936) described the oocysts of Isospora hemidactyli in the house-gecko, Hemidactylus mabouia, from Salto de Itu, State of São Paulo, Brazil and figured the parasite as developing in the cytoplasm of the epithelial cells of the small intestine. In our redescription of this coccidian in the same species of gecko from Belém, north Brazil, however, we showed that development of all the endogenous stages is, in fact, in the nuclei of the gut epithelial cells (Lainson \& Paperna 1999). It is the object of this paper to describe their ultrastructure.

Among the described Isospora of lizards, intranuclear development appears to be more common than intracytoplasmic development (Finkelman \& Paperna 1994a,b,1995). It is not peculiar to saurian isosporans, however, as intranuclear development of the endogenous stages has been reported for species of Eimeria in cattle (Davis et al. 1957); Cyclospora of the European mole (Mohamed \& Molyneux 1990); Tyzzeria of birds (Shibalova \& Morozova 1979); Eimeria (s.l.) of amphibians (Pellerdy 1974) and Eimeria (s.1.) of fish (Paperna 1995). All the endogenous stages of avian Isospora spp., so far studied, have been

Work supported by a grant from the Wellcome Trust, London (RL).

${ }^{+}$Corresponding author. Fax: +55-91-226.1284

Received 10 May 1999

Accepted 29 September 1999 shown to develop in the host-cell cytoplasm, including those examined by electron microscopy (Milde 1979).

To date, available literature concerning the ultrastructure of reptilian Isospora spp., includes a study of the endogenous development of $I$. chalcidis in the lizard Chalcides ocellatus from Egypt (El Toukhy et al. 1996); a review paper on species of Isospora of Asian and Australian lizards (Paperna \& Finkelman 1999); a description of junction zones formed between the parasitophorous vacuole and the nucleolemma of nuclei occupied by the young meronts of an Isospora sp. in the gecko Hemidactylus binoei (Paperna \& Vilenkin 1999) and a description of the endocytoplasmic merogony of an unidentified isosporan from the Australian gecko, Gehyra variegata (Schmidt et al. 1967).

\section{MATERIALS AND METHODS}

Maintenance of geckos and detection of infected specimens was as previously described (Lainson \& Paperna 1999). Infected hosts were killed with ether and the small intestine removed. This was cut longitudinally into two halves, one of which was checked for the location of endogenous stages following the examination of fresh squash preparations between slide and cover-slip. Infected parts of the other half of the intestine were fixed in $2.5 \%$ glutaraldehyde in cacodylate buffer $(0.1 \mathrm{M}$, $\mathrm{pH}$ 7.4) for $24 \mathrm{~h}$ at $4^{\circ} \mathrm{C}$, rinsed repeatedly in the same buffer, post-fixed in $1 \%$ osmium tetroxide in the same buffer for $1 \mathrm{~h}$ and, after rinsing in the buffer, dehydrated in graded ethyl alcohol dilutions and embedded in Agar 100 medium (Agar Scien- 
tific Ltd, UK). Thin sections, cut on a Reichert 'Ultracut' microtome with a diamond knife, were stained on grids with uranyl acetate and lead citrate and examined with a Jeol 100CX transmission electron microscope.

\section{RESULTS}

The earliest stages observed were elongated, uninucleate meronts (Fig. 1) whose cytoplasm contained many large mitochondria, several lipid vacuoles, a very conspicuous adnuclear organelle ('paragolgi body') adjacent to the meront nucleus, and food vacuoles containing a crystaloid substance. Dividing meronts also contained many mitochondria and a few lipid vacuoles, and on one occasion a dividing meront was seen to be sending a protrusion with a lipid vacuole, out into the surrounding substance of the host-cell nucleus (Fig. 2 ). Adnuclear organelles were very conspicuous in the more advanced division stages (Fig. 3). These meronts contained variable amounts of amylopectin granules and their nuclei appeared to be of different size, suggesting that division was asynchronous. Some of the newly formed merozoites within the parent meront in the parasitophorous vacuole possessed more than one nucleus (Fig. 4). These merozoites contained a variable number of electron dense bodies (cross-sectioned rhoptries or rhoptry anlagen) and a few amylopectin granules (Figs 4, 5): micronemes apparently occurred only in the uninucleate forms. The meront residuum at this late stage of development contained large lipid vacuoles which became lobulated, or even fragmented (Fig. 5).

Figs 6-8 show three stages in the development of the microgamonts, with the cytoplasm containing a few electron-dense bodies, variable amounts of amylopectin granules, centrioles in the future sites of microgamete production and Golgi apparatus (Fig. 8). A fully mature microgamont, shedding microgametes is illustrated in Fig. 9.

We were able to find only late stage macrogamonts (zygotes) in the material studied (Figs 10, 11). They were loaded with amylopectin granules and contained sets of canaliculi and two types of wall-forming bodies (W1 and W2), both of which are homogenously electron-dense. The size of the type 1 bodies was fairly large, with some almost reaching that of type 2 . Within their endoplasmic reticulum cisternae the W2 bodies were embedded, together with smaller globules of similar consistency, in a layer of lower density ground substance. The host-cell nucleus retained its integrity up to the late stages of merogony and gametogony, becoming reduced to a thin residual layer simultaneously with degeneration and shrinkage of the host-cell cytoplasm (Fig. 6).

\section{DISCUSSION}

The fine structure of the developing stages of I. hemidactyli in the nuclei of the gut epithelial cells of $H$. mabouia conforms generally with that observed in other intranuclear species of Isospora described in other saurian hosts (Paperna \& Finkelman 1999). The only exception is a parasite from an agamid lizard of Australia which has a unique and different process of merogony (Finkelman \& Paperna 1994a, Paperna \& Finkelman 1999).

Although several images of host-cell nuclei invaded by single merozoites were available in the present study, none showed evidence of junction zones between the PV wall and the nucleolemma, as observed in the early intranuclear infections of an Isospora sp. in another gecko, Hemidactylus binoei (Paperna \& Vilenkin 1999). One developing meront of $I$. hemidactyli was seen, however, to be sending a cytoplasmic protrusion, together with its PV-wall coat, into the surrounding host-cell nucleoplasm, possibly for nutritional purposes.

Size difference among the nuclei of some maturing meronts suggests a lack of synchrony in the sequence of nuclear division and could account for the finding of more than one nucleus in some merozoites. This in turn suggests that some merozoites begin or accomplish nuclear division before invading a new host cell and transforming into another meront, or even before becoming detached from their parent meront. This is reminiscent of the binary or endodyogenous division seen in merozoites of Eimeria (s.1.) vanesi, during or soon after their differentiation (Paperna 1991). Multinucleate merozoites have also been observed in the avian coccidian E. magna (Danford \& Hammond 1972).

Transmission electron microscope images of developing microgamonts of $I$. hemidactyli were similar to those of eimerians in general. With regards the late stage macrogamonts (zygotes), the finding of type 2 wall-forming bodies which, together with smaller globules of similar consistency, are embedded in a layer of ground-substance of lower density, suggests a gradual disintegration of the type 2 bodies in the course of contributing substances for the oocyst wall formation.

A similar process was observed in the zygotes of Isospora spp. in some geckos and agamids from Australia, but was absent in those studied in levantine geckos (Paperna \& Finkelman 1999).

\section{ACKNOWLEDGEMENTS}

To Marina Schein (Department of Animal Sciences, Faculty of Agriculture, Hebrew University of Jerusalem) and Constância Maia Franco and Manoel C de Souza (Instituto Evandro Chagas, Belém) for technical assistance. 


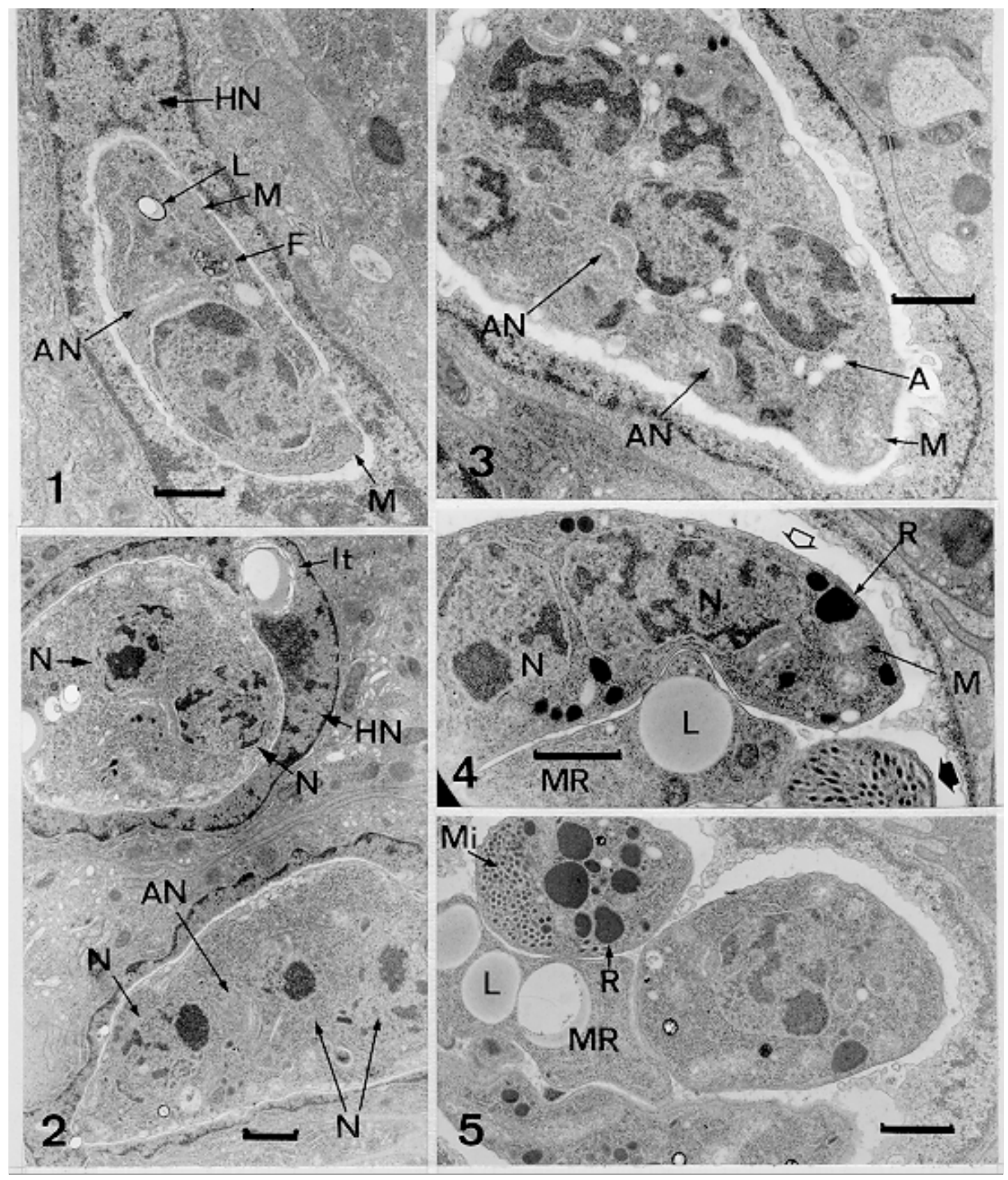

Intranuclear merogony stages of Isospora hemidactyli in Hemidactylus mabouia. Fig. 1: young, elongated meront. Fig. 2: rounded, dividing meronts. Note the protrusion of one meront into the host nucleoplasm (It). Fig. 3: pre-mature meront with six nuclei in cross-section. Fig. 4: progeny of a differentiated meront comprised of uninucleate merozoites (bold arrow) and a polynucleate merozoite (hollow arrow) with a meront residuum (MR). Fig. 5: portion of another segmented meront. Bars $=10 \mu \mathrm{m}$. A: amylopectin granules; AN: adnuclear organelle; F: food vacuole; HN: host-cell nucleus; It: protrusion of parasite and PV wall into the host-cell nucleoplasm; L: lipid vacuole; M: mitochondria; Mi: micronemes; N: parasite nuclei; R: rhoptries (or rhoptry anlagen); 

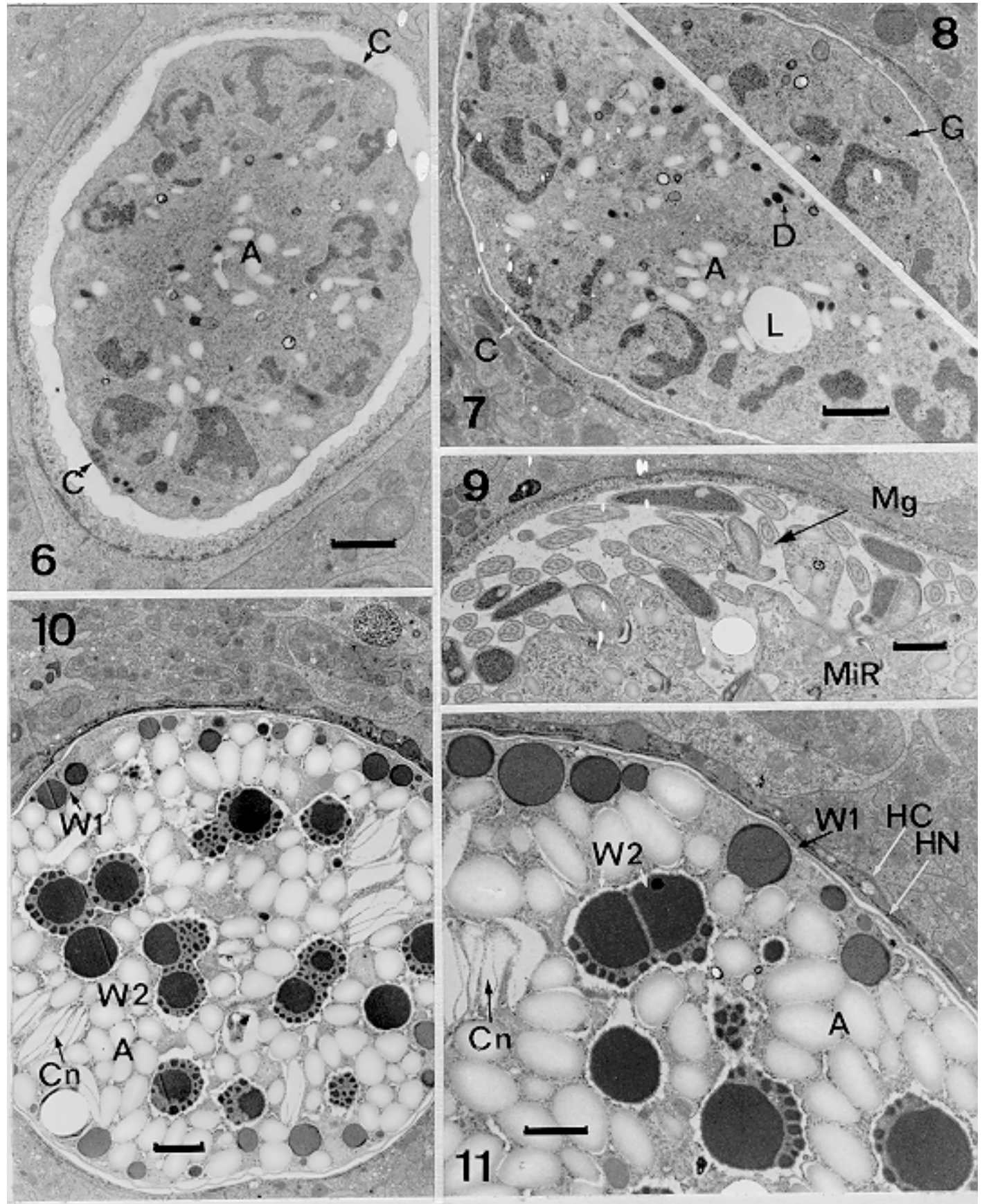

Gamogony stages of Isospora hemidactyli. Figs 6-8: differentiating microgamonts. Fig. 9: microgametes on the microgamont surface. Figs 10-11: late stage macrogamont (zygote). Note the disintegrating type 2 wall-forming bodies (W2), and the degeneration of both the host-cell cytoplasm $(\mathrm{HC})$ and the host-cell nucleus $(\mathrm{HN})$. Bars $=10 \mu \mathrm{m}$. A: amylopectin granules; C: centriole site; $\mathrm{Cn}$ : canaliculi; D: electron-dense granules; G: golgi apparatus; HC: host-cell cytoplasm; L: lipid vacuole; Mg: microgametes; MiR: microgamont residuum; W1: type 1 wall-forming bodies; W2: type 2 wall-forming bodies. 


\section{REFERENCES}

Carini A 1936. Sur une Isospora de l'intestin de l'Hemidactylus mabujae. Ann Parasit Hum Comp 14: 444-446.

Danforth HD, Hammond DH 1972. Stages in merogony in multinucleate merozoites of Eimeria magna Perard, 1925. J Protozool 19: 454-457.

Davis LR, Bowman GW, Boughton DC 1957. The endogenous development of Eimeria alabamensis Christensen 1941, an intranuclear coccidium of cattle. J Protozool 4: 225-229

El Toukhy AAG, Aziz AA, Gawad MAM 1996. Light and electron microscopy studies of Isospora chalcidis (Amoudi, 1989) infecting Chalcides ocellatus in Egypt. J Egypt Soc Parasitol 26: 79-91.

Finkelman S, Paperna I 1994a. The endogenous development of three new intranuclear species of Isospora (Apicomplexa: Eimeriidae) from agamid lizards. Syst Parasitol 127: 213-226.

Finkelman S, Paperna I 1994b. The endogenous development of two new species of Isospora Schneider, 1881 (Apicomplexa: Eimeriidae) from Thai geckoes. Syst Parasitol 30: 213-221.

Finkelman S, Paperna I 1995. The endogenous development of two new species of Isospora (Apicomplexa: Eimeriidae) from skinks. Syst Parasitol 27: 227-235.

Lainson R, Paperna I 1999. Re-descriptions of Isospora ameivae Carini, 1932 in the teiid lizard Ameiva ameiva and Isospora hemidactyli Carini, 1936 in the gecko Hemidactylus mabouia, with particular reference to their endogenous stages. Mem Inst Oswaldo
Cruz 94: 459-466.

Milde K 1979. Light and electron microscopic studies on isosporan parasites (Sporozoa) in sparrows (Passer domesticus). Protistologica 15: 607-627.

Mohamed HA, Molineux DH 1990. Developmental stages of Cyclospora talpa in the liver and bile duct of the mole (Talpa europea). Parasitology 101: 345350.

Paperna I 1991. Fine structure of Eimeria (s.1.) vanasi merogony stages in the intestinal mucosa of cichlid fishes. Dis Aquat Org 10: 195-201.

Paperna I 1995. Ultrastructure and developmental affinities of piscine coccidia. Dis Aquat Org 22: 6776.

Paperna I, Finkelman S 1999. The fine structure of reptilian Isospora species with intranuclear endogenous development. Parassitologia, in press.

Paperna I, Vilenkin M 1999. Parasitophorous vacuole of intranuclear Coccidia maintain membranous junction with the host-cell cytoplasm. Folia Parasitol, in press.

Pellerdy LP 1974. Coccidia and Coccidiosis, 2nd ed., Paul Parey, Berlin, Hamburg, 959 pp.

Schmidt K, Johnston MRL, Stehbens WE 1967. Fine structure of the schizont and the merozoite of Isospora sp. (Sporozoa: Eimeriidae) parasitic in Gehyra variegata (Dumeril and Bibron, 1836) (Reptilia: Gekkonidae). J Protozool 14: 602-608.

Shibalova TA, Morozova TI 1979. Intranuclear development of macrogametes in the coccidium Tyzzeria parvula. Tsitologia (Leningrad) 21: 969-972 (in Russian). 